\title{
OS SENTIDOS DA COMUNICAÇÃO NA ESCOLA: as contribuições da filosofia da educação para este debate
}

Cláudia Chaves FONSECA ${ }^{1}$

\begin{abstract}
Resumo
Diversas concepções entram em disputa quando os processos comunicacionais e/ou midiáticos ocupam lugar na escola. Como recursos didáticos, instrumentos de marketing educativo ou, ao inverso, quando são eles mesmos são objetos de crítica, esses processos representam tanto uma promessa quanto um desafio, carentes de construções conceituais que revelem sua importância na escola. Busca-se o amparo da Filosofia da Educação porque é uma área com múltiplas perspectivas de modo que o pesquisador, ao estudar os problemas da escola, apoia-se tanto na tradição quanto na abertura para a reflexão que é própria da disciplina. Esta disciplina nos ajuda a compreender de que maneira, em certas linhas do pensamento educacional, elabora-se um discurso comunicacional e como ele é construído conceitualmente. O entendimento da inter-relação entre educação e comunicação, sob a perspectiva filosófica, justifica-se pela urgência do tema. Foram examinadas, de maneira comparada, as filosofias da educação de John Dewey (1859-1952), Célestin Freinet (1896-1966) e Paulo Freire (1921-1997) no que dizem respeito à fundamentação conceitual da comunicação.
\end{abstract}

Palavras-chave: Filosofia da Educação. Comunicação. John Dewey. Célestin Freinet. Paulo Freire.

\footnotetext{
${ }^{1}$ Doutora em Educação (PUC Minas), Mestre em Comunicação (UFMG) e Bacharel em Jornalismo (UFMG). Professora universitária e pesquisadora.

E-mail: claufon@gmail.com
} 


\title{
THE MEANINGS OF COMMUNICATION IN SCHOOLS: the contibutions of the philosophy of education to this debate
}

Cláudia Chaves FONSECA

\begin{abstract}
Many different conceptions contend when communication and/or media processes take place in schools. When used as didactic resources, tools of educational marketing or, on the contrary, when they are themselves the subjects of criticism, these processes represent both promise and challenge, in need of conceptual development in order to reveal their importance in schools. We are supported by the Philosophy of Education because it's a field of knowledge with multiple perspectives so that a researcher, when studying educational issues, is supported both in tradition as well as by the openness to reflection which is a trait of this discipline. This discipline helps us understand how, in certain schools of educational thought, a communicational discourse is built and how it is conceptually constructed. The understanding of the mutual relation between education and communication, from a philosophical viewpoint, is justified by the subject's urgency. We examined, comparatively, the educational philosophies of John Dewey (1859-1952), Célestin Freinet (1896-1966) and Paulo Freire (1921-1997) regarding their conceptual formulations on communication.
\end{abstract}

Keywords: Philosophy of Education. Communication. John Dewey. Célestin Freinet. Paulo Freire. 


\section{Introdução}

Nas instituições escolares, há algumas décadas, a comunicação disputa um lugar simbólico, pretendendo legitimação como fonte de conhecimento. Entende-se por comunicação, na escola, os recursos didáticos midiáticos utilizados nas aulas e laboratórios; mas considera-se igualmente comunicação as ações de marketing e propaganda desenvolvidas pelas instituições para posicionarem-se no mercado com vistas à atração e fidelização de alunos. Também não deixam de serem entendidas como comunicação as reuniões com os pais, os eventos escolares, palestras, os grupos de mães no aplicativo Whatsapp ou mesmo o momento das aulas. Até no planejamento didático a comunicação está presente, uma vez que as sequências didáticas (SD) de determinadas disciplinas podem ser vistas, em alguma medida, como a organização pedagógica de narrativas de saberes. Todos os exemplos citados são de situações vividas e, talvez por isso, fiquem no âmbito do não-questionado, a não ser quando são qualificados em termos de juízos de valor: a "boa" comunicação (aquela que facilita o ensino, como um programa de computador didático) ou a "má” comunicação (quando acontece cyberbullying, por exemplo).

O objetivo deste artigo, portanto, é problematizar o conceito de comunicação na escola, buscando as contribuições da Filosofia da Educação que possam nos auxiliar a estabelecer um debate a respeito da inserção da comunicação na escola. O termo problema é tomado neste texto no sentido de questão, como algo que ainda não foi pensado ou o foi de modo insuficiente apesar de, no caso da comunicação, ser tão frequente na vida cotidiana escolar. Justamente pela grande demanda e repercussão das situações comunicacionais na escola é que elas merecem ser problematizadas, uma vez que têm acarretado desafios e incômodos pedagógicos: pais, professores, gestores e os próprios alunos muitas vezes não sabem como lidar com a comunicação mesmo estando submetidos à sua onipresença.

A separação tradicional entre espaço social e espaço escolar, bem como entre saberes curriculares e não-curriculares está se desfazendo, e é exatamente por isso que estudar a confluência entre Educação e Comunicação se faz necessário. O entendimento da inter-relação entre educação e comunicação, sob a perspectiva filosófica, justifica-se pela relevância e pela urgência do tema. A Filosofia da Educação, ao buscar os pressupostos, os horizontes e os limites da educação, pensa a respeito do assunto em suas diversas implicações, incluindo a dimensão comunicativa, uma vez que educar é tarefa coletiva e social, pertinente às várias dimensões da sociabilidade humana.

Neste trabalho, que é resultado de tese de doutorado em Educação defendida em 2017, recorre-se a esta disciplina para compreender de que maneira, em certas linhas do pensamento educacional contemporâneo, elabora-se um discurso comunicacional e como ele é construído conceitualmente. A tese examinou, de maneira comparada, as filosofias da educação de John Dewey (Estados Unidos, 1859-1952), Célestin Freinet (França, 1896-1966) 
e Paulo Freire (Brasil, 1921-1997) exclusivamente no que dizem respeito à fundamentação conceitual da comunicação na obra dos autores. Um dos motivos para a escolha destes autores foi a menção explícita à comunicação em seus escritos, bem como a consideração que deram a ela como conceito.

Discorrer a respeito da comunicação na instituição escolar é pensar simultaneamente a respeito da comunicação no interior, sobre e para a escola, indicando uma razão comunicacional que perpassa o ambiente educativo, fazendo-o incorporar lógicas e práticas. Charlot (2006) afirma que o campo científico da Educação seria uma área de circulação e entrecruzamento de saberes:

\begin{abstract}
O que é específico da educação como área de saber é o fato de ela ser uma área na qual circulam, ao mesmo tempo, conhecimentos (por vezes de origens diversas), práticas e políticas. Delimita-se assim uma primeira definição da disciplina educação ou ciências da educação: é um campo de saber fundamentalmente mestiço, em que se cruzam, se interpelam e, por vezes, se fecundam, de um lado, conhecimentos, conceitos e métodos originários de campos disciplinares múltiplos e, por outro lado, saberes, práticas, fins éticos e políticos. O que define a especificidade da disciplina é essa mestiçagem, essa circulação. (CHARLOT, 2006, p. 9).
\end{abstract}

Entre as tensões que permeiam o campo educacional estão os processos comunicacionais, seja em sua mediação nos processos interpessoais, seja em sua dimensão midiática. A Filosofia da Educação é um campo que vai fornecer o horizonte conceitual para que se compreenda de que maneira, em certas linhas do pensamento educacional contemporâneo, elabora-se um lugar para a comunicação e como este lugar é construído conceitualmente.

\title{
Pensar a comunicação em sua relação com a cultura
}

Para refletirmos a respeito da comunicação na escola - e aqui nos referimos tanto à comunicação no interior da escola, sobre a escola e no contexto social em que a escola atua - é fundamental nos ampararmos na Teoria da Comunicação.

Em 1987, quando escreveu o livro Dos meios às mediações: comunicação, cultura e hegemonia (1997), o culturalista espanhol Jesús Martín-Barbero propôs uma metodologia para minimizar o impasse que há muitas décadas atormentava os estudiosos da comunicação: ora os fenômenos comunicacionais eram estudados de maneira "exterior", por suas consequências no meio social, ora os estudos ficavam centrados exclusivamente nos elementos internos constituintes dos processos comunicativos. No primeiro caso, as premissas do fenômeno de comunicação eram consideradas como dados, de modo que se esperava, com a investigação, esclarecer tão somente seus efeitos e impactos no meio social. Os estudos de caráter sociológico não apreendiam o fenômeno comunicativo por si mesmo, pois não havia clareza a respeito do seu objeto. Essa maneira de pensar predominou desde o início da disciplina nos anos 1920 até meados da década de 1960. 
Tentava-se tomar de empréstimo, para os estudos de comunicação, as abordagens teóricometodológicas funcionalistas.

No segundo caso, polo oposto, a comunicação era tomada como um evento separado do meio em que acontecia, como se tais elementos estivessem "suspensos" e isolados da historicidade. A mensagem comunicativa era tomada como um universo em si mesmo, preso em uma teia de linguagem a ser decifrada. Esses estudos de cariz semiótico e linguístico foram importantes para o desenvolvimento da disciplina nas décadas de 1960 e 1970. A Teoria da Comunicação ficou assim enredada em teorias aporéticas, que limitaram seu alcance explicativo.

O deslocamento proposto por Martín-Barbero e outros autores dizia respeito a analisar as questões do campo evitando privilegiar alternadamente o polo da emissão ou o polo da recepção. Ele afirmou que não buscava apenas uma inversão do olhar, mas que os pesquisadores formulassem a análise dos fenômenos comunicativos a partir da cultura. Afirma o autor:

Uma reconceitualização da cultura que nos confronta com essa outra experiência cultural que é a popular, em sua existência múltipla e ativa não apenas na memória do passado, mas também na conflitividade e na criatividade atuais. Pensar os processos de comunicação neste sentido, a partir da cultura, significa deixar de pensá-los a partir das disciplinas e dos meios. (MARTIN-BARBERO, 1997, p. 285).

O conhecimento do contexto cultural permitiria ao investigador situar a comunicação em uma perspectiva ampla, levando em consideração aspectos, como as situações de audiência, as interações durante a audiência, entre outros, muitas vezes negligenciados nas correntes de pensamento já estabelecidas. Conceber a comunicação como um fenômeno mediado na cultura, com, para ou até mesmo apesar dela.

O conceito de mediação, descrito pelo autor como "lugares dos quais provêm as construções que delimitam e configuram a materialidade social e a expressividade cultural da televisão"2 (MARTíN-BARBERO, 1997, p. 292) tornou-se importante para a compreensão da dinâmica comunicacional, que mais recentemente tem sido radicalmente transformada diante das realidades criadas pelos meios digitais. O lugar social dos receptores é tão fundamental para o estudo da comunicação quanto a mensagem por ela mesma. A respeito disso comenta França (2006, p. 70): “Descobre-se que os indivíduos, na relação com a mídia, trazem os condicionamentos de suas outras interseções, e que estas interseções atuam no indivíduo". O conceito de mediação também relembrou aos teóricos que a comunicação não é somente um conjunto de processos de interação a serem descritos, mas um objeto científico socialmente encarnado, cuja complexidade exige que seja pensado, debatido e investigado.

Seriam mediadores todos os elementos pertinentes aos processos comunicativos, pois é a relação comunicativa que se tornaria a partir de então objeto de estudo. Desse

${ }^{2} \mathrm{O}$ autor menciona a televisão porque seu estudo é centrado na análise deste meio de comunicação, mas isso não impede que sua proposta teórica seja ampliada para a compreensão dos demais meios. 
modo, entende-se que condicionantes socioculturais como, por exemplo, a escolaridade dos interlocutores, influenciam no tipo de comunicação e em sua forma de operar e vice-versa, de modo que há uma indissolubilidade entre comunicação e cultura. Os elementos isolados pouco têm a dizer ao pesquisador, mas sim a dinâmica estabelecida entre eles. Assim, percebemos que o termo “comunicação” é polissêmico, abrangendo inúmeras modalidades de interação, em contextos espaço-temporais específicos e interlocutores os mais diversos. Por isso mesmo, no espaço público diversas concepções a respeito da comunicação estão em disputa na busca do estabelecimento de um sentido.

\section{Dewey: educação e mediação comunicacional}

A questão comunicacional está presente na educação pelo menos desde as últimas décadas do século XIX. Os movimentos de renovação educacional que remontam àquele período de uma maneira ou de outra levam em consideração aspectos comunicacionais na prática pedagógica. A comunicação, em suas múltiplas manifestações, destaca-se como um conceito importante na obra pedagógica de autores como John Dewey (1859-1952), Célestin Freinet (1896-1966) e Paulo Freire (1921-1997), entre outros. Estes três autores, embora tenham vivido e trabalhado em tempos e locais diferentes, possuem vínculos com os movimentos de renovação educacional, seja na sua formulação (Dewey e o movimento da Escola Nova), ampliação (Freinet e a Escola Moderna Francesa) ou crítica (Freire e a Pedagogia do Oprimido).

John Dewey, no primeiro capítulo do livro Democracia e educação (1916), intitulado "Educação como necessidade da vida”, afirmou que o social não se constitui sem a educação, e que esta é tão importante na vida cultural quanto o alimento e a reprodução para a vida biológica. Ele define educação como "uma reconstrução ou reorganização da experiência, que esclarece e aumenta o sentido desta e também a nossa aptidão para dirigirmos o curso das experiências subsequentes” (DEWEY, 1959, p. 83). Ora, para que a experiência seja reconstruída ou reorganizada, ela necessita ser comunicada, pois é em associação que os homens conferem sentido ao meio em que vivem.

Ao propor uma concepção ampliada de democracia na qual este modo de governar não é somente o funcionamento de um conjunto de estruturas formais já dispostas, mas uma construção contínua daqueles que dela participam, o autor propugnou a importância da educação escolar como uma instituição na qual o cidadão se exercitaria no convívio social, eminentemente permeado pela comunicação. De fato, a vida social é composta de interações, e muitas delas são discordantes de modo que a educação seria um "campo de controvérsias” (DEWEY, 2011, p. 13). Ao serem educados, os homens constroem a continuidade social, seja para perpetuá-la ou alterá-la. O autor se propôs, então, a conceber as interações como objetos de conhecimento também na educação e foi um dos pioneiros, em língua inglesa, a usar explicitamente o termo comunicação (VARÃO; CUNHA, 2014). 
A noção de comunicação foi se constituindo em sua obra através dos anos, em um primeiro momento de forma naturalizada, mas em seguida com maior complexidade, articulada às noções de linguagem e significação. Pode-se ressaltar, entre diversas passagens, o capítulo “Natureza, comunicação e significado”, do livro Experiência e natureza, escrito em 1884, no qual o autor discute a comunicação como uma habilidade sem a qual a experiência social se daria em um nível extremamente precário, portanto, qualificar a comunicação seria também qualificar os processos democráticos. Também pode ser destacado o décimo sexto capítulo de Como pensamos, de 1910, intitulado "A linguagem e o treino do pensamento”, em que a relação entre pensamento e linguagem é analisada semioticamente e também vários trechos, além do citado acima, de Democracia e educação.

Dewey exalta a comunicação como uma realização na qual é possível a constituição do social:

Dentre todas as realizações, a comunicação é a mais notável. Trata-se de um prodígio, diante do qual a transubstanciação se torna pálida, que as coisas passem a ser capazes de transferir-se do plano das impulsões externas para o do desvelamento para o homem, e assim para si próprias; que o resultado da comunicação possa ser a participação e o ato de compartilhar. (DEWEY, 1985, p. 29).

Por que seria a comunicação tão prodigiosa? Na perspectiva deweyana, a resposta estaria na capacidade que este processo social teria de ampliar a experiência humana, tanto em extensão ou amplitude (“breadth”) quanto em profundidade (“depth”). A amplitude e a profundidade seriam atributos da experiência: na primeira, a experiência é alargada em agência e adaptação humanas e na segunda (profundidade) quando tem a capacidade de conferir significado aos acontecimentos. Quando nos comunicamos, transformamos nossos impulsos vitais em nomeações, conferindo-lhes sentido e, mais do que isso, projetamos o sentido em direção a outrem de modo que cabe à relação entre os interlocutores estabelecer um sentido em comum. É pela comunicação que nos associamos, saindo da esfera puramente individual em busca de alteridade na construção de um horizonte interlocutivo. A ideia do sentido em comum é fundamental para a inter-relação entre educação e comunicação porque não há como educar sem estabelecer um terreno dialógico, um mínimo denominador comum para que a experiência do aluno seja ampliada e aprofundada, tornando-se educativa. A experiência educativa ocorre no indivíduo, mas tem profundo impacto social.

O autor faz uma acurada análise da linguagem, afastando a noção de que as palavras serviriam somente para nomear o mundo, como se fossem “espelho” dele:

Onde existe a comunicação, as coisas, adquirindo significado, adquirem, por intermédio deste, representantes, substitutos, signos e implicações, os quais se apresentam como infinitamente mais dóceis para o manejo, mais permanentes e mais aptos quanto à acomodação, relativamente aos eventos em seu estado anterior. (DEWEY, 1985, p. 29). 
No processo comunicativo, as palavras não se referem diretamente às coisas, mas à ideia dessas mesmas coisas, uma vez que a palavra é presença vicária, torna presente aquilo que está ausente. As interações ocorreriam, portanto, por meio de simbolismos. A relação entre pensamento e linguagem não é direta:

\begin{abstract}
A linguagem exprime o pensamento, mas não primariamente, nem desde o começo, mesmo quando é consciente. A primeira razão de ser da linguagem é atuar (pela manifestação do desejo, da emoção e do pensamento) na atividade de outras pessoas; em segundo lugar, serve para favorecer relações sociais mais íntimas; seu emprego como veículo consciente do pensamento e do saber só vem em terceiro lugar e é relativamente tardio. (DEWEY, 1959, p. 236).
\end{abstract}

A comunicação humana, para o autor, seria então um processo de sociabilidade e de reflexividade social. Comunicar é agir em prol do estabelecimento de um sentido em comum nunca alcançado, mas sempre almejado.

Definido o processo comunicativo, Dewey também se preocupou com a comunicação coletiva, apontando suas relações com a formação de uma opinião pública. Segundo ele, nem sempre o desenvolvimento tecnológico encontra-se sintonizado com a democratização das relações sociais e os meios de comunicação. O excesso e a fragmentação das informações podem levar ao conformismo, à confusão do público e ao embotamento do pensamento reflexivo:

\begin{abstract}
A imprensa, o telégrafo, o telefone e o rádio alargaram indefinidamente a ordem de informações à disposição da pessoa comum. Seria inépcia negar que disto resultou um certo despertar de mentes naturalmente indolentes. Mas, pondo-se inteiramente de lado o fato de se terem aberto novas avenidas pelas quais pode continuamente operar a propaganda organizada para despertar a emoção e deixar atrás de si um saldo de opinião - cabe notar que há muita informação sobre que o juízo não é solicitado a responder, e que, mesmo se o quisesse fazer, não seria efetivamente possível, tão dispersivo é o material sobre que seria chamado a se aplicar. (DEWEY, 1970, p. 137).
\end{abstract}

\title{
Educação e comunicação em Freinet
}

Outro autor que conferiu importância à comunicação na escola foi o pedagogo francês Célestin Freinet, conhecido na tradição pedagógica como fomentador do uso do jornal escolar. Vigora, em certas leituras de sua obra, uma perspectiva romântica de suas propostas, talvez pelo fato de que o próprio autor tenha se valido de parábolas para exprimir suas ideias como em Pedagogia do bom senso, livro escrito em 1949. Não obstante não ter trilhado uma carreira acadêmica, Freinet publicou diversos livros, podendo-se admitir que tenha formulado uma filosofia da educação na qual a comunicação tem lugar privilegiado.

É necessária certa cautela, no entanto, para compreender a noção de comunicação freinetiana. Longe de ser um conceito abstrato, a comunicação, no pensamento do autor, é uma forma de ação e uma técnica de vida, traduzida em atividades como a imprensa escolar, o livro da vida, a correspondência interescolar, o jornal mural, a biblioteca de 
trabalho, etc. A comunicação é tomada em uma perspectiva materialista, de cunho político, em situações concretas por interlocutores determinados.

Freinet iniciou o trabalho com o jornal escolar na década de 1920. Professor de área rural, com grandes limitações físicas (foi ferido durante a Primeira Guerra Mundial), o autor buscava uma forma de reproduzir o texto dos alunos. Foi inspirado pelo pedagogo belga Decroly, que já havia feito anteriormente uma experiência com jornal escolar anos.

Sua definição de jornal escolar é a seguinte: "uma coletânea de textos livres para crianças, expressão fiel da turma e do seu meio” (FREINET, 1976, p. 18). O autor distingue "jornal escolar" de "jornal na escola”, uma vez que o primeiro se caracteriza por uma perspectiva pedagógica da escola do trabalho:

O jornal escolar é uma 'produção', uma obra ao alcance das nossas classes e que toca profundamente no essencial da nossa vida educativa. Põe-nos no caminho de uma fórmula nova de escola, aquela escola do trabalho cuja necessidade começamos a sentir, que já não trabalha segundo normas intelectualizadas, mas sim com base numa atividade social. (FREINET, 1976, p. 86).

O objetivo do jornal escolar não seria emular os jornais tradicionais, informativos, mas abrir uma possibilidade de expressão infantil, para dar às crianças autoconfiança. A técnica do jornal escolar possuía uma dupla finalidade: dar concretude ao esforço de escrita do aluno, fazendo-o redigir o texto para um destinatário, marcando o papel social da escrita; ao mesmo tempo em que poderia desmistificar, para os alunos pobres com os quais lidava o autor, a palavra impressa, o poder do jornal escrito pelas classes hegemônicas. O jornal escolar, portanto, era visto por Freinet como um modo de afirmação da cidadania infantil:

Uma das grandes deficiências da nossa cultura - e a escola teve pelo menos participação nela - é o caráter de tabu que o impresso assume para as crianças e os adultos da nossa época. O jornal, principalmente, é tabu. Está escrito!... Está impresso! Não estaria no jornal se fosse falso! (FREINET, 1976, p. 110).

Ao serem capazes de produzir um jornal, os alunos perceberiam a lógica de produção da imprensa, posicionando-se como sujeitos produtores de cultura; o jornal seria uma ferramenta de exercício da dialogicidade na sala de aula e para fora dela. A autoconfiança adquirida com a produção do jornal reforçaria o valor social da criança. É a finalidade política, na mais ampla acepção deste termo, que oferece a medida e o significado da comunicação na educação para Freinet.

Se, em relação à comunicação como processo coletivo, a perspectiva freinetiana é pragmática e política, em relação aos meios de comunicação de massa percebe-se certa ambiguidade em sua obra, fato notado por alguns comentadores. Para ele, o uso do jornal e de outras técnicas na escola nunca é gratuito, mas revela-se um ato pedagógico e político. Os meios de comunicação coletiva, no entanto, seriam um desafio ao professor porque em sua concepção seriam veículos de poder, opressivos: 
Em que medida a educação periescolar auxilia a ação da escola? Há a máxima necessidade de se ter em conta a influência da família em regime capitalista, e a influência de todas as forças obscurantistas cujos esforços se conjugam no sentido da manutenção de uma ordem social única: o cinema, o rádio, a imprensa - com os seus jornais para crianças e seus livros alienatórios para adultos - os seus livros de cordel e as suas revistas malsãs[...]. (FREINET, C. apud FREINET, E., 1978, p. 281).

Por essa razão, caberia ao educador exercer a intencionalidade pedagógica ao lidar com os meios de comunicação, reconhecendo a presença deles e a sua importância na vida das crianças, mas, ao mesmo tempo, exercendo a crítica, numa visão emancipatória. Ao comentar a respeito do rádio escolar, por exemplo, Freinet afirmou:

Também nos agrada constatar que as emissões de rádio vão passar de simples distração que são para autênticas lições. Apenas se trata de um outro tipo de lições que terão que ser concebidas de acordo com uma nova técnica. Essa técnica é a que nós preconizamos e preparamos. Não teremos dificuldade em completar os elementos de estudo que nos trazem as 'ondas escolares' graças ao nosso ficheiro e à nossa biblioteca de trabalho. É aí que se revela a importância e a necessidade destes novos utensílios (FREINET, C. apud FREINET, E., 1978, p. 407, grifo nosso).

Dessa forma, a comunicação é um dos quatro eixos da pedagogia freinetiana porque revela-se como um espaço de contradição que tanto pode levar à emancipação coletiva quanto à alienação. Freinet tomou a comunicação simultaneamente como uma prática e um tópico de pensamento, problematizando-a. Para o autor, a comunicação na escola aproxima esta última da contemporaneidade, renovando as concepções pedagógicas bem como favorecendo a cidadania infantil.

\section{Paulo Freire: rumo a uma pedagogia da comunicação}

Apesar de não se considerar um teórico da comunicação, o educador brasileiro Paulo Freire, em sua obra, discutiu tanto o fenômeno quanto o conceito, seja como processo humano primário e/ou em sua vertente tecnológica: os chamados meios de comunicação. Na conversa com Sérgio Guimarães, publicada no livro Sobre educação (diálogos) (1984), Freire e Guimarães tecem várias considerações a respeito da mídia e do jornalismo na sociedade e na área de interesse de ambos: a escola. Em período anterior quando estava exilado no Chile, Freire escreveu Extensão ou Comunicação (1968), considerado o livro no qual discorreu mais detalhadamente a respeito do tema. Além disso, em Educação como Prática da Liberdade (1976) chamou a atenção dos educadores para o fato de que a comunicação é uma construção humana e, portanto, precisa ser ensinada: “ [...] precisávamos de uma Pedagogia da Comunicação com que vencêssemos o desamor acrítico do diálogo” (FREIRE, 1976, p. 108).

Freire tem muito a nos ensinar a respeito da comunicação, sejamos nós educadores, comunicadores ou membros do público. Em Comunicação e Cultura: as ideias de Paulo Freire (1981), Venício Lima, estudioso deste tema na obra freireana, afirma que uma das 
razões pelas quais as ideias do educador pernambucano são fundamentais para o diálogo entre os campos da Educação e Comunicação seria a de que:

(...) A maior parte do trabalho de Freire é devotada explicitamente ao problema da educação, ou àquilo que ele chama de ação cultural, o que traz implicações diretas para os estudiosos da comunicação, em pelo menos dois níveis. Ao nível filosófico, o próprio Freire equipara educação com comunicação, uma vez que não utiliza ambos os termos indistintamente, mas também os iguala em sua epistemologia. Ao nível social, os sistemas de comunicação - sobretudo de comunicação de massa - podem ser considerados como tendo a mesma função simbólico-ideológica dos sistemas educacionais nas sociedades capitalistas. (LIMA, 1981, p. 10-11).

Lima adverte, no entanto, que Freire foi (e continua sendo) um autor menosprezado nas ciências da Comunicação, uma vez que a tradição de estudos da área foi fundada pela matriz funcionalista ou behaviorista. Somente a partir da década de 1980, a indissolubilidade entre comunicação e cultura foi mais bem compreendida conforme foi descrito no início deste texto.

A educação, para Freire, define-se como diálogo:

O diálogo com as massas não é concessão, nem presente, nem muito menos uma tática a ser usada, como a sloganização o é, para dominar. O diálogo, como encontro de homens para a 'pronúncia' do mundo, é uma condição fundamental para a sua real humanização. (FREIRE, 1975, p. 160).

Diálogo pressupõe intersubjetividade, troca, imersão no universo cultural de outrem.

Nessa perspectiva, o diálogo se funda na comunicação e dialeticamente a transforma, pois são inseparáveis. O homem educado seria aquele que conquistou os elementos para a "pronúncia” da realidade em que vive. Ele não é mais objeto, mas sujeito de seu ser social:

Aprender a ler e escrever deve se constituir numa oportunidade para que os homens conheçam o verdadeiro significado da expressão dizer a palavra: um ato humano que implica reflexão e ação. Como tal, trata-se de um direito humano primordial, e não privilégio de uns poucos. Dizer a palavra não é um ato verdadeiro a menos que esteja simultaneamente associado ao direito de autoexpressão e expressão do mundo, de criar e recriar, de decidir e escolher e, em última análise, de participar do processo histórico da sociedade. (FREIRE, 2007, p.12).

Educação e comunicação estão, pois, entranhadas uma à outra. Ambas são relações sociais e políticas:

Os homens não podem ser verdadeiramente humanos sem a comunicação, pois são criaturas essencialmente comunicativas. Impedir a comunicação equivale a reduzir o homem à condição de 'coisa'... Somente através da comunicação é que a vida humana pode adquirir significado. (FREIRE, 1975, p. 122).

O importante, então, seria compreender qual o sentido preciso que a comunicação adquire no pensamento de Freire, uma vez que o autor não aceita uma leitura instrumental identificada somente com a técnica (no sentido de se constituir apenas em meios, canais ou procedimentos a serem aplicados para se comunicar). De acordo com ele, a comunicação seria uma prática humana que deve ser vivida, estudada a partir de uma matriz cultural. A 
comunicação é realizada no terreno do simbólico entre seres humanos espacial e historicamente referenciados na busca do compartilhamento de sentidos.

Para esclarecer a concepção freireana, no livro Extensão ou Comunicação (2010), o autor afirma o “equívoco gnosiológico” dos agrônomos e técnicos agrícolas que atuavam na área rural chilena de tentarem impor a modernização de práticas de cultivo e criação sem levar em consideração os saberes prévios dos camponeses e sua experiência vivida. Freire usou o termo “extensão” para denominar aquilo que a comunicação, a seu ver, não é:

(...) Na medida em que, no termo extensão, está implícita a ação de levar, de transferir, de entregar, de depositar algo em alguém, ressalta, nele, uma conotação indiscutivelmente mecanicista. Mas, como este algo que está sendo levado, transmitido, transferido (para ser, em última instância, depositado em alguém - que são os camponeses) é um conjunto de procedimentos técnicos, que implicam em conhecimento, que são conhecimento, se impõem as perguntas: será o ato de conhecer aquele através do qual um sujeito, transformado em objeto, recebe pacientemente um conteúdo do outro? Pode este conteúdo, que é conhecimento de, ser 'tratado' como se fosse algo estático? Estará ou não submetendo o conhecimento a condicionamentos histórico-sociológicos? Se a pura tomada de consciência das coisas não constitui ainda um 'saber cabal', já que pertence à esfera da mera opinião (doxa), como enfrentar a superação desta esfera por aquela em que as coisas são desveladas e se atinge a razão das mesmas? (FREIRE, 2010, p. 26).

O termo “extensão” é empregado por Freire não apenas no sentido de extensão rural, mas como uma metáfora de certo modo de interação no qual alguns sujeitos consideram os outros como objetos, recusando-lhes o papel de interlocutores. Quando há uma situação de extensão, o saber é propagandístico, é retirado dele qualquer possibilidade de comunicação, uma vez que se fazem verticalmente “comunicados”. De fato, a ideia de "transmitir algo a alguém”, tão presente tanto nas teorias pedagógicas quanto nas teóricas comunicativas mais conservadoras, transformaria o saber "vivo" em saber "morto”. A verticalidade da extensão impede a emancipação dos sujeitos, uma vez que fecha o caminho para que, por meio da ação, o homem se recrie.

A comunicação - prática humana por excelência - é construída justamente no sentido oposto. Na comunicação até pode haver hierarquia entre os interlocutores, mas aquela é fundada no reconhecimento recíproco, no respeito, e não na dominação ou no autoritarismo. Comunicar-se exige disposição, esforço, atitude, enfrentamento de diferenças. Na extensão o mundo do outro é invadido, com vistas à dominação simbólica; na comunicação o mundo do outro é compreendido com vistas à emancipação mútua. Comunicação, para Freire, é caminho para a ação. Para o autor, “o homem não é uma ilha. É comunicação. Logo há uma estreita ligação entre comunhão e busca” (FREIRE, 2010, p. 28).

Ao se referir à necessidade de uma pedagogia da comunicação, Paulo Freire deixou indicado o lugar central deste tema em sua filosofia educacional. De acordo com ele, a comunicação autêntica era fundada no diálogo e não se reduzia à mera informação unilateral. A esse respeito, afirmou Escola: 
A dimensão intersubjetiva que subjaz à noção de comunicação (pôr em comum, participar, comungar), ao contrário da mera transmissão de informação, unilateral, reclama o concurso e a participação ativa do outro, como sujeito e interlocutor. Se a uma pedagogia da comunicação não é legítimo rasurar a dimensão informativa, não poderá, no entanto, deixar que esta obnubile os sentidos originais da comunicação. (ESCOLA, 2004, s/n).

A filosofia da educação de Paulo Freire, no que diz respeito à comunicação, se fundamenta na premissa da reciprocidade. A educação somente acontece quando se reconhece o outro, o saber do outro. O professor se educa para educar, ele também aprende e exercita a comunicação para que o diálogo se efetive. Nem aluno, nem professor podem pensar sozinhos, pois a comunicação só existe na interação, que dá corpo ao pensamento.

Freire também chama nossa atenção para os processos comunicativos na prática pedagógica. O professor precisa se colocar no lugar do outro, daquele seu aluno que ora por diante será seu interlocutor. É por esse motivo que a questão comunicacional é crucial na pedagogia do autor. No livro Medo e ousadia (2001) ${ }^{3}$ Freire e o educador norte-americano Ira Shor dialogam sobre como efetivar a mudança na educação. Em certo momento, Shor pergunta a Freire o que ele faria na segunda-feira pela manhã, ou seja, queria saber o que fazer de fato para iniciar uma transformação na escola. O educador brasileiro responde afirmando que não há fórmula mágica para tanto. Depende de uma atitude dialógica do professor. É pela comunicação dialógica que os diferentes procedimentos e as variadas técnicas educativas vão tomando forma, sem que se constituam em modelos estanques. O professor libertador mais escuta do que fala. Recusa a verticalidade do seu saber. Não abre mão de seu papel diretivo, mas não se comporta como um ditador. Professor e aluno estão em relação dialética: "a diferença libertadora é uma tensão que o professor tenta superar por uma atitude democrática com relação à sua diretividade” (FREIRE, 1976, p. 24).

\title{
Considerações finais
}

De acordo com França (2006), o estudo da comunicação acontece quando o investigador apreende os sujeitos em comunicação, e não os sujeitos da comunicação. Trata-se de uma nuance importante, uma vez que, segundo a autora, a experiência comunicativa é essencialmente relacional: o sentido não seria o resultado de uma interação, mas a interação mesma é que configura os sentidos:

\begin{abstract}
A abordagem comunicacional busca desvelar, nos fenômenos sociais, a presença da comunicação enquanto momento constituidor. Seu objetivo é apreender as relações comunicativas, relações estabelecidas pelas práticas simbólicas, como um espaço de agenciamento e escolha; um embate de forças. Este embate é a experiência comunicativa. (FRANÇA, 2006, p. 85).
\end{abstract}

${ }^{3}$ FREIRE, P; SHOR, I. Medo e ousadia: o cotidiano do professor. 9 a . ed. Rio de Janeiro: Paz e Terra, 2001. 
Nestes tempos em que as instituições escolares se veem desafiadas por diversas situações que envolvem processos comunicacionais como, por exemplo, o uso de celulares em sala de aula, entre tantas outras, é importante revisitar os filósofos da educação para que nos inspirem a lidar com os problemas de hoje e tentar solucioná-los. Afirma França:

A comunicação é a ação de afetar e ser afetado pelo outro através de materiais significantes. É produzir/consumir discursos, representações, sentidos para e em decorrência do outro - e sofrer, junto com ele (embora não necessariamente igual a ele) as consequências. (FRANÇA, 2006, p. 86).

Dewey, Freinet e Freire compreenderam que os processos comunicacionais, a partir do contexto em que viviam eram (e viriam a ser cada vez mais) cruciais na escola contemporânea, dada a inserção dos meios de comunicação na vida cotidiana. Talvez por isso buscaram entender a inter-relação mídia-educação em seus aspectos culturais. Eles igualmente desenvolveram o tema da linguagem numa perspectiva ampliada como troca social e compartilhamento de simbolismos. Cada um, dentro da linha de pensamento que lhe foi própria, erigiu a comunicação como objeto de pensamento no interior de seus interesses específicos a respeito da educação e da escola. A comunicação foi problematizada como questão escolar, ao lado de tantas outras, por implicar em alterações no processo de ensino-aprendizagem.

Dewey destaca o caráter relacional de todo processo comunicativo, que é a um só tempo tanto consumatório (uma finalidade em si mesmo) quanto instrumental (um instrumento para que se alcance algum objetivo). As interações humanas estão no mundo simbólico. Os signos não somente nos ajudam a nomear e nos orientar no mundo, mas também a ampliar nossa experiência. A educação, como tarefa inscrita na cultura, só fará jus a este nome se for fundamentada em interações que contemplem amplitude e profundidade das experiências de modo a elevar a qualidade delas na vida concreta dos alunos.

A comunicação é um dos pilares da concepção de Freinet a respeito da educação. Reconhecido como incentivador da técnica da imprensa escolar destaca-se na obra do autor, de maneira geral, o entendimento da comunicação não somente como mídia, mas, principalmente, como um pretexto para a afirmação da cidadania infantil por meio da expressão de sua personalidade e identidade. Para ele, os alunos viviam imersos na nova realidade comunicacional, trazida pelo jornal, cinema e rádio e, portanto, não poderiam desenvolver-se como cidadãos plenos se não conhecessem a lógica de funcionamento desses meios. A autoexpressão e a auto-organização dos indivíduos passariam, agora, pelo seu domínio dos recursos comunicativos.

Paulo Freire propõe que todos os envolvidos no desafio de educar assumam a tarefa de construir uma pedagogia da comunicação. Esta pedagogia envolve os processos educacionais em sala de aula, que são igualmente processos de interação. Que tipo de interação temos construído com os alunos? Quais as interações são encorajadas e quais negligenciadas na escola? Podemos afirmar que a escola em que atuamos é realmente uma 
comunidade comunicativa ("sujeitos em comunicação") ou uma realidade em que os sujeitos são comunicados ("sujeitos da comunicação”)? Para o autor, a pedagogia da comunicação se inicia na sala de aula, mas se expande para todos os âmbitos sociais, envolvendo inclusive uma crítica de mídia.

Os três autores são reflexivos em relação aos meios de comunicação de massa. Para eles, as condições de comunicabilidade no mundo contemporâneo, apesar de terem sido ampliadas por estes meios, não foram efetivadas. A ênfase na informação e não no diálogo, seu volume desmedido, a fragmentação das percepções, o consumismo, a propaganda, são características que imperam na lógica de funcionamento da mídia. Essa contradição atravessa nossa experiência comunicativa, inclusive aquela que acontece na escola. É por isso que este tema carece de discussão e também de implantação de propostas de democratização para que as instituições escolares se reafirmem como espaços de diálogo e mudança social nos quais seus atores sejam legítimos interlocutores.

\section{Referências}

CHARLOT, B. A pesquisa educacional entre conhecimentos, políticas e práticas: especificidades e desafios de uma área de saber. Rev. Bras. de Educação. V.11, n. 31, jan/abr. 2006.

DEWEY, J. Como pensamos: como se relaciona o pensamento reflexivo com o processo educativo: uma reexposição. $3^{\text {a }}$. ed. São Paulo: Cia. Editora Nacional, 1959.

DEWEY, J. Democracia e Educação: introdução à filosofia da educação. $3^{\text {aa }}$ ed. São Paulo: Cia. Editora Nacional, 1959.

DEWEY, J. Liberalismo, liberdade e cultura. São Paulo: Cia. Editora Nacional, 1970.

DEWEY, J. Experiência e natureza. 2ª. ed. São Paulo: Abril Cultural, 1985. (Col. Os Pensadores).

DEWEY, J. Experiência e educação. 2a . ed. Petrópolis/RJ: Vozes, 2011.

ESCOLA, J. Paulo Freire e Gabriel Marcel. Esboço de uma pedagogia da comunicação na era da informação. Disponível http://www.acervo.paulofreire.org:8080/jspui/bitstream/7891/3890/1/FPF_PTPF_01_0609. pdf. Acesso em 22/07/2018. s/d

FRANÇA, V. Sujeito da comunicação, sujeitos em comunicação. In: GUIMARÃES, C.; FRANÇA, V. (orgs.). Na mídia, na rua: narrativas do cotidiano. Belo Horizonte: Autêntica, 2006.

FREINET, C. As técnicas Freinet da escola moderna. $4^{\mathrm{a}}$ ed. Lisboa, Portugal: Estampa, 1976.

FREINET, C. O jornal escolar. Lisboa, Portugal: Estampa, 1976.

FREINET, E. Nascimento de uma pedagogia popular: os métodos Freinet. Lisboa, Portugal: Estampa, 1978.

FREIRE, P. Pedagogia do Oprimido. 3ª . ed. Rio de Janeiro: Paz e Terra, 1975.

FREIRE, P. Educação como prática de liberdade. 6a․ ed. Rio de Janeiro: Paz e Terra, 1976.

FREIRE, P. Ação cultural para a liberdade e outros escritos. 12ª ed. Rio de Janeiro: Paz e Terra, 2007. 
FREIRE, P. Extensão ou comunicação? Rio de Janeiro: Paz e Terra, 2010.

FREIRE, P; GUIMARÃES, S. Sobre educação (diálogos). Vol. 2., Rio de Janeiro: Paz e Terra, 1984.

LIMA, V. Comunicação e cultura: as ideias de Paulo Freire. $2^{\mathrm{a}}$. ed. Rio de Janeiro: Paz e Terra, 1981.

MARTÍN-BARBERO, J. Dos Meios às mediações: comunicação, cultura e hegemonia. $2^{\mathrm{a}}$. ed. Rio de Janeiro: Ed. UFRJ, 1997.

MENDONÇA, R. F. A liberdade de expressão em uma chave não-dualista: as contribuições de John Dewey. In: GUIMARÃES, J.; AMORIM, A. P. (orgs.) A corrupção na opinião pública: uma defesa republicana da liberdade de expressão. São Paulo: Boitempo, 2013.

VARÃO, R.; CUNHA, R. O conceito de comunicação em John Dewey: de 1884 a 1927. In: Comunicologia, Brasília, s/n, out. 2014.

Recebido em: 04/03/2019

Aprovado em: 06/04/2020 